Review

\title{
An Alternative Use of Horticultural Crops: Stressed Plants as Biofactories of Bioactive Phenolic Compounds
}

\author{
Daniel A. Jacobo-Velázquez ${ }^{1}$ and Luis Cisneros-Zevallos ${ }^{2, *}$
}

1 Department of Biotechnology and Food Engineering, School of Biotechnology and Food, Centro de Biotecnologia-FEMSA, Tecnologico de Monterrey-Campus Monterrey, E. Garza Sada 2501 Sur, C.P. 64849, Monterrey, N.L., Mexico; E-Mail: djacobov@itesm.mx

2 Vegetable \& Fruit Improvement Center, Department of Horticultural Sciences, Texas A\&M University, College Station, TX 77843, USA

* Author to whom correspondence should be addressed; E-Mail: 1cisnero@tamu.edu; Tel.: +979-845-3244; Fax: +979-845-0627.

Received: 1 August 2012; in revised form: 13 September 2012 / Accepted: 14 September 2012 / Published: 24 September 2012

\begin{abstract}
Plants subjected to abiotic stresses synthesize secondary metabolites with potential application in the functional foods, dietary supplements, pharmaceutical, cosmetics and agrochemical markets. This approach can be extended to horticultural crops. This review describes previous reports regarding the effect of different postharvest abiotic stresses on the accumulation of phenolic compounds. Likewise, the physiological basis for the biosynthesis of phenolic compounds as an abiotic stress response is described. The information presented herein would be useful for growers and the fresh produce market which are interested in finding alternative uses for their crops, especially for those not meeting quality standards and thus are considered as waste.
\end{abstract}

Keywords: postharvest abiotic stresses; plants as biofactories; carrots; chlorogenic acid; dicaffeoylquinic acids; physiological stress response; stress signaling molecules

\section{Introduction}

The use of plants to target the synthesis of secondary metabolites with health-promoting properties has shown several advantages when compared with other available production technologies. Genetic engineering is the most commonly used tool to generate crop lines with enhanced concentrations of 
desirable chemicals [1]. However, the use of genetically modified plants is limited because in most cases they are considered as potential biological hazards that create an ecological imbalance [2]. Taking this into account, alternative technologies are needed to use plants for the production of bioactive compounds. The application of postharvest abiotic stresses in fresh fruits and vegetables induces the accumulation of antioxidants [3]. This approach can be exploited as an effective alternative to genetic manipulation (Figure 1). Nevertheless, little is known on the physiological and molecular basis for the accumulation of antioxidants as a postharvest stress response. Increasing the scientific knowledge in this area is critical to envisage strategies that permit the effective use of crops as biofactories of nutraceuticals.

Figure 1. Comparison between genetic engineering and postharvest abiotic stresses as secondary metabolites overexpression strategies.
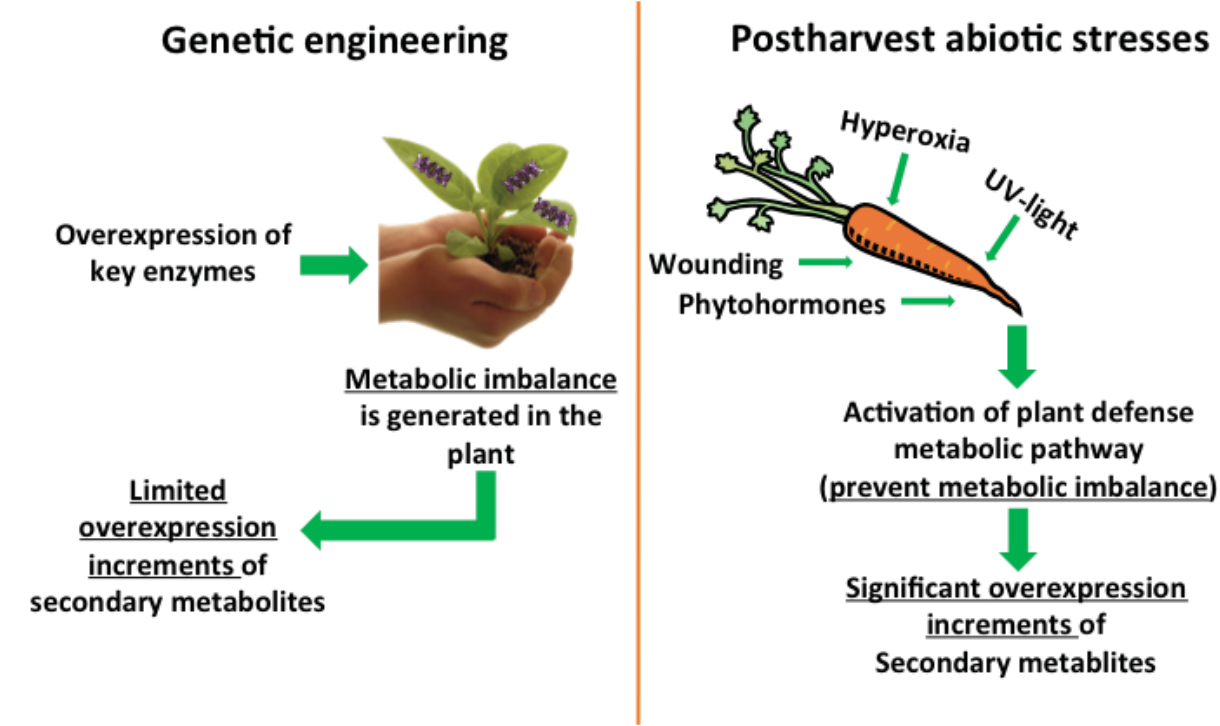

The use of postharvest abiotic stresses on extensively grown crops for the production of secondary metabolites with health-promoting properties is of scientific, economical and social interest. In our research group we have already demonstrated that carrots respond to wounding stress accumulating phenolic compounds mainly hydroxycinnamic acids [4-7]. In addition, we have observed that the wound-induced accumulation of individual phenolic compounds can be affected by the application of an additional abiotic stress in the wounded-tissue provoking modifications in the total amount and type of phenolic compounds accumulated [4,8-11]. This strategy is proposed as an alternative to metabolic engineering (Figure 1).

In this paper the physiological and molecular basis for the stress-induced accumulation of phenolic compounds in plants is reviewed. The information presented is useful for growers interested in finding alternative uses for their crops. For instance, growers would be able to use fresh produce that does not meet quality standards (considered as waste), as starting material for phenolics production.

\section{Plants as Biofactories of Phenolic Compounds: Use of Abiotic Stresses}

In the last few years the use of plants to produce chemical compounds with health-promoting properties has been extensively studied. Numerous crop plants such as potato, rice, tomato, among 
others, have been genetically engineered to produce higher levels of antioxidants [12-14]. However, metabolic engineering is technically complex and the extensive cultivation of genetically modified crops has been questioned due to potential environmental and safety issues [2]. The use of abiotic stresses is a practical and effective technology that allows the accumulation of antioxidants in plants (Figure 1). Among these antioxidants produced and accumulated as a stress response, phenolics have been identified as those with the highest potential to protect against different degenerative diseases $[15,16]$.

The effect of different postharvest abiotic stresses (i.e., wounding, UV-light, hyperoxia, and the exogenous application of ethylene and methyl jasmonate) on the accumulation of phenolic compounds in fruits and vegetables has been evaluated in several studies. Reyes and Cisneros-Zevallos [17] evaluated the accumulation of phenolic compounds in purple-flesh potatoes subjected to ethylene (ET), methyl jasmonate (MJ), temperature, light, and wounding stress. The authors determined that only wounding stress induced the accumulation of total phenolics ( $60 \%$ of increase) in purple-flesh potatoes. Likewise, Reyes et al. [18] determined that the wound-induced accumulation of phenolic compounds depends on the type of fruit and vegetable tissue. The authors found that tissues with lower initial levels of reduced ascorbic acid and total phenolics responded to wounding stress with higher accumulation of phenolics as compared with the other evaluated tissues. Furthermore, Heredia and Cisneros-Zevallos [8] determined that combining wounding with additional stresses such as the exogenous application of ET and MJ in wounded lettuce, celery, red onion, carrots and jicama tissues enhances the wound-induced accumulation of phenolic antioxidants. However, the physiological and molecular basis for this stress response remains unknown.

From the studies mentioned above $[8,17,18]$, it was determined that carrot is a plant tissue that responds to different postharvest abiotic stresses. Therefore, carrot was used in subsequent investigations as a model system to study on detail the effect of applying different abiotic stresses such as the exogenous application of ET and MJ [9], UV-light radiation [4], hyperoxia [11] on the accumulation of phenolic compounds of tissue subjected to different wounding intensities (wholes, slices, pie-cuts, and shreds). The authors determined that the application of wounding stress is needed to activate the metabolic mechanisms of the plant. In addition, the wound-induced accumulation of phenolic compounds in carrots was greatest in the tissues with the highest wounding intensity. Furthermore, the authors observed that ET, MJ, UV-light or hyperoxia, applied in the wounded-carrot tissue enhances the wound-induced accumulation of phenolic compounds. For instance, Heredia and Cisneros-Zevallos [9] determined that wounding stress increases $\sim 75 \%$ the phenolic content in shredded-carrots stored $6 \mathrm{~d}$ at $15{ }^{\circ} \mathrm{C}$. This wound-induced accumulation of phenolics was found to be enhanced to $\sim 150 \%$ and $\sim 200 \%$ when exogenous MJ (250 ppm) and ET (1000 ppm) were applied in the shredded-carrots, respectively. Similarly, Surjadinata [4] stated that the application of UV-C light (60 $\mathrm{W} \times 50 \mathrm{~cm}$ distance) for $15 \mathrm{~min}$ in shredded-carrots increases by $\sim 15 \%$ the wound-induced accumulation of phenolic compounds after storing carrots $4 \mathrm{~d}$ at $15{ }^{\circ} \mathrm{C}$.

These investigations on the application of abiotic stresses on wounded carrot tissue [4,9] were performed in order to evaluate different approaches to increase the nutraceutical content of fresh-cut fruits and vegetables. Jacobo-Velázquez et al. [11] studied a similar approach to evaluate the potential use of carrots as biofactories of phenolics. This approach involves the application of extreme conditions of stresses in fruits and vegetables to produce high levels of phenolics as a stress response. 
The phenolic compounds produced as a stress-response can be subjected to downstream processing and used by the pharmaceutical and dietary supplements industries. Jacobo-Velázquez et al. [11] exposed carrots to extreme conditions of wounding in combination with hyperoxia $\left(80 \% \mathrm{O}_{2}\right)$ stresses. The authors determined that when shredded-carrots are stored at $20{ }^{\circ} \mathrm{C}$ under hyperoxia conditions the phenolic content in the tissue can be increased in $\sim 550 \%$ after $48 \mathrm{~h}$ of storage. Likewise, the authors stated that the shredded-carrots treated with hyperoxia produce $90 \%$ more phenolic compounds than the air treated samples.

\subsection{Carrots as Biofactories of Hydroxycinnamic Acids}

Carrots respond to wounding stresses synthesizing hydroxycinnamic acids. Previous work in our group identified the presence of CQA and tentatively CQA derivatives in wounded carrot tissue [7-9]. Furthermore, Jacobo-Velázquez et al. [11] confirmed the identity and presence of the isomers 3,5-diCQA and 4,5-diCQA in extracts obtained from wounded carrot tissue and analyzed by HPLC-ESI-MS $^{n}$. The application of additional stresses such as ET, MJ, UV-light and hyperoxia in wounded-tissue induces modifications in the phenolic profiles of carrots. The results of these investigations are summarized in Table 1. The following sections describe the effect of applying ET, MJ, UV-light, and hyperoxia on the accumulation of individual phenolic compounds (CQA, 3,5-diCQA, 4,5-diCQA) in wounded carrot tissue. Additionally, the potential health benefits of these phenolic compounds are briefly mentioned.

\subsubsection{Chlorogenic Acid (CQA)}

The CQA is the phenolic compound accumulated in the largest amounts as a response to wounding stress in carrots. This phenolic is extensively absorbed and metabolized in humans [19-21] and has several pharmaceutical applications. Clinical studies have demonstrated that CQA can be used to decrease the absorption of glucose and reduce the body mass of overweight and obese people [22]. Additionally, CQA has anti-hepatitis B virus activity [23] and inhibitory effect on brain-tumor progression [24]. The concentration of CQA in carrots can be significantly increased from $\sim 16.2 \mathrm{mg} / \mathrm{kg}$ to $\sim 440-920 \mathrm{mg} / \mathrm{kg}$ by the application of wounding stress. This increase depends on the storage conditions of the wounded tissue such as temperature. For instance, when shredded-carrots are stored at $15{ }^{\circ} \mathrm{C}$ for $4 \mathrm{~d}$, the concentration of CQA is increased by $\sim 70 \%$ [11]. On the other hand, when shredded-carrots are stored at $15^{\circ} \mathrm{C}$ for $6 \mathrm{~d}$, the concentration of CQA is increased by $\sim 320 \%$ [9]. The wound-induced accumulation of CQA can be increased by $47 \%, 16 \%$, and $31 \%$ when shredded-carrots are treated with exogenous ET $(1000 \mathrm{ppm})$, hyperoxia $\left(80 \% \mathrm{O}_{2}\right)$ and UV-light $(60 \mathrm{~W}$ at $50 \mathrm{~cm}$ below the lamp for $15 \mathrm{~min}$ ) stresses, respectively. The exogenous application of MJ (250 ppm) produces an inhibitory effect on the wound-induced accumulation of CQA in shredded carrots. Samples treated with MJ can accumulate $27 \%$ less CQA compared with wounding alone. 
Table 1. Effect of different abiotic stresses (wounding, UV-light, ethylene, and methyl jasmonate) on the accumulation of individual phenolic compounds in carrots.

\begin{tabular}{|c|c|c|c|c|c|c|}
\hline \multirow[t]{2}{*}{ Compound } & \multirow{2}{*}{$\begin{array}{l}\text { Abiotic stress } \\
\text { applied }\end{array}$} & \multirow{2}{*}{$\begin{array}{l}\text { Storage } \\
\text { conditions }\end{array}$} & \multicolumn{2}{|c|}{$\begin{array}{l}\text { Phenolic content } \\
\text { (mg/100 g FW) }\end{array}$} & \multirow{2}{*}{$\begin{array}{c}\text { Increase } \\
(\%)\end{array}$} & \multirow[t]{2}{*}{ Reference } \\
\hline & & & Before * & After & & \\
\hline \multirow{4}{*}{ Chlorogenic acid } & $\mathrm{W}$ & $4 \mathrm{~d} / 15^{\circ} \mathrm{C}$ & 5.3 & 44.70 & 743 & [4] \\
\hline & $\mathrm{W}+\mathrm{UV}-\mathrm{C}$ & $4 \mathrm{~d} / 15^{\circ} \mathrm{C}$ & 5.3 & 75.52 & 1324 & {$[4]$} \\
\hline & $W+E$ & $6 \mathrm{~d} / 15^{\circ} \mathrm{C}$ & 14.8 & 92.6 & 526 & [9] \\
\hline & $\mathrm{W}+\mathrm{H}$ & $2 \mathrm{~d} / 20{ }^{\circ} \mathrm{C}$ & 1.62 & 68.8 & 4148 & [11] \\
\hline \multirow{4}{*}{ 4,5-Dicaffeoylquinic acid } & $\mathrm{W}$ & $4 \mathrm{~d} / 15^{\circ} \mathrm{C}$ & 4.59 & 13.23 & 188 & {$[4]$} \\
\hline & $\mathrm{W}+\mathrm{UV}-\mathrm{C}$ & $4 \mathrm{~d} / 15^{\circ} \mathrm{C}$ & 4.59 & 14.00 & 205 & {$[4]$} \\
\hline & $W+E$ & $6 \mathrm{~d} / 15^{\circ} \mathrm{C}$ & 3.2 & 28.1 & 778 & [9] \\
\hline & $\mathrm{W}+\mathrm{H}$ & $2 \mathrm{~d} / 20{ }^{\circ} \mathrm{C}$ & 0.13 & 7.1 & 6191 & [11] \\
\hline \multirow{3}{*}{ 3,5-Dicaffeoylquinic acid } & $\mathrm{W}$ & $4 \mathrm{~d} / 15^{\circ} \mathrm{C}$ & nd & 4.91 & - & {$[4]$} \\
\hline & $\mathrm{W}+\mathrm{UV}-\mathrm{C}$ & $4 \mathrm{~d} / 15^{\circ} \mathrm{C}$ & nd & 6.03 & - & {$[4]$} \\
\hline & $\mathrm{W}+\mathrm{H}$ & $2 \mathrm{~d} / 20{ }^{\circ} \mathrm{C}$ & nd & 1.65 & - & [11] \\
\hline
\end{tabular}

Abbreviations: $\mathrm{W}=$ wounding, $\mathrm{E}=$ ethylene, $\mathrm{H}=$ hyperoxia, $\mathrm{FW}=$ fresh weight; * Initial values of individual phenolics are variety dependent; Data shown was obtained from independent studies $[4,9,11]$.

\subsubsection{Chlorogenic Acid Derivatives: 4,5-diCQA and 3,5-diCQA.}

The CQA derivatives (dicaffeoylquinic acids, diCQA) 4,5-diCQA and 3,5-diCQA are highly bioavailable in humans [21]. These compounds have particular pharmaceutical importance since they can be used as an anti-HIV drug [25,26] as well as for the treatment of jaundice and hepatic failure [27]. In addition, the diCQA derivatives can potentially be used as a drug to prevent neurodegenerative diseases related to oxidative stress such as Alzheimer and Parkinson [28]. Although the 3,5-diCQA is not present in non-stressed carrot tissue, the application of wounding stress induces the de novo synthesis of this phenolic compound. Approximately $49.1 \mathrm{mg} / \mathrm{kg}$ of 3,5-diCQA can be produced in shredded-carrots after their storage at $15{ }^{\circ} \mathrm{C}$ for $4 \mathrm{~d}$. The wound-induced accumulation of 3,5-diCQA in shredded-carrots is not significantly affected by the application of hyperoxia [11] and UV-light [4] stresses. The concentration of 4,5-diCQA in carrots is $\sim 1.3-45.0 \mathrm{mg} / \mathrm{kg}$ and it can be increased to $\sim 132 \mathrm{mg} / \mathrm{kg}$ in shredded carrots after $4 \mathrm{~d}$ of storage at $15{ }^{\circ} \mathrm{C}$. The wound-induced accumulation of 4,5-diCQA in carrots can be affected by the application of additional stresses. For instance, the application of ET can induce $~ 19 \%$ higher accumulation of 4,5-diCQA in shredded carrots [9]. Other stresses such as UV-light and hyperoxia do not affect the accumulation of this phenolic compound [4,11]. The exogenous application of MJ in shredded-carrot tissue inhibits the wound-induced accumulation of 4,5-diCQA by $50 \%$ [9].

\section{Physiological and Molecular Basis for the Accumulation of Phenolics as a Stress Response}

The accumulation of high levels of hydroxycinnamic acids in stressed-carrots is the result of the activation of different metabolic events that collectively exploits the genetic potential of the tissue to synthesize phenolic compounds. It is well known that wounding stress activates the phenylpropanoid 
metabolism in carrots to produce lignin and suberin during wound healing [29]. Lignin is composed of monolignols residues that are synthesized from hydroxycinnamic acids precursors [30]. Since carrots accumulate hydroxycinnamic acids, it is implied that these phenolics are synthesized at a higher rate compared with their rate of utilization.

The synthesis of hydroxycinnamic acids and lignin induced by wounding stress in carrots has to be the result of the activation of the phenylpropanoid metabolism together with those metabolic pathways involved in the supplementation of carbons skeletons such as respiration, glycolysis, oxidative pentose phosphate pathway (OPPP), and shikimate pathway (Figure 2). Different signaling molecules, such as ET, jasmonic acid (JA), and reactive oxygen species (ROS) have been reported to be produced by wounding stress as well as to activate plant defense genes, including those from the phenylpropanoid metabolism [31]. The following sections review previous findings regarding the metabolic events involved in the wound-induced accumulation of phenolics in plants.

Figure 2. Plant metabolic mechanism used for the biosynthesis of phenolics.

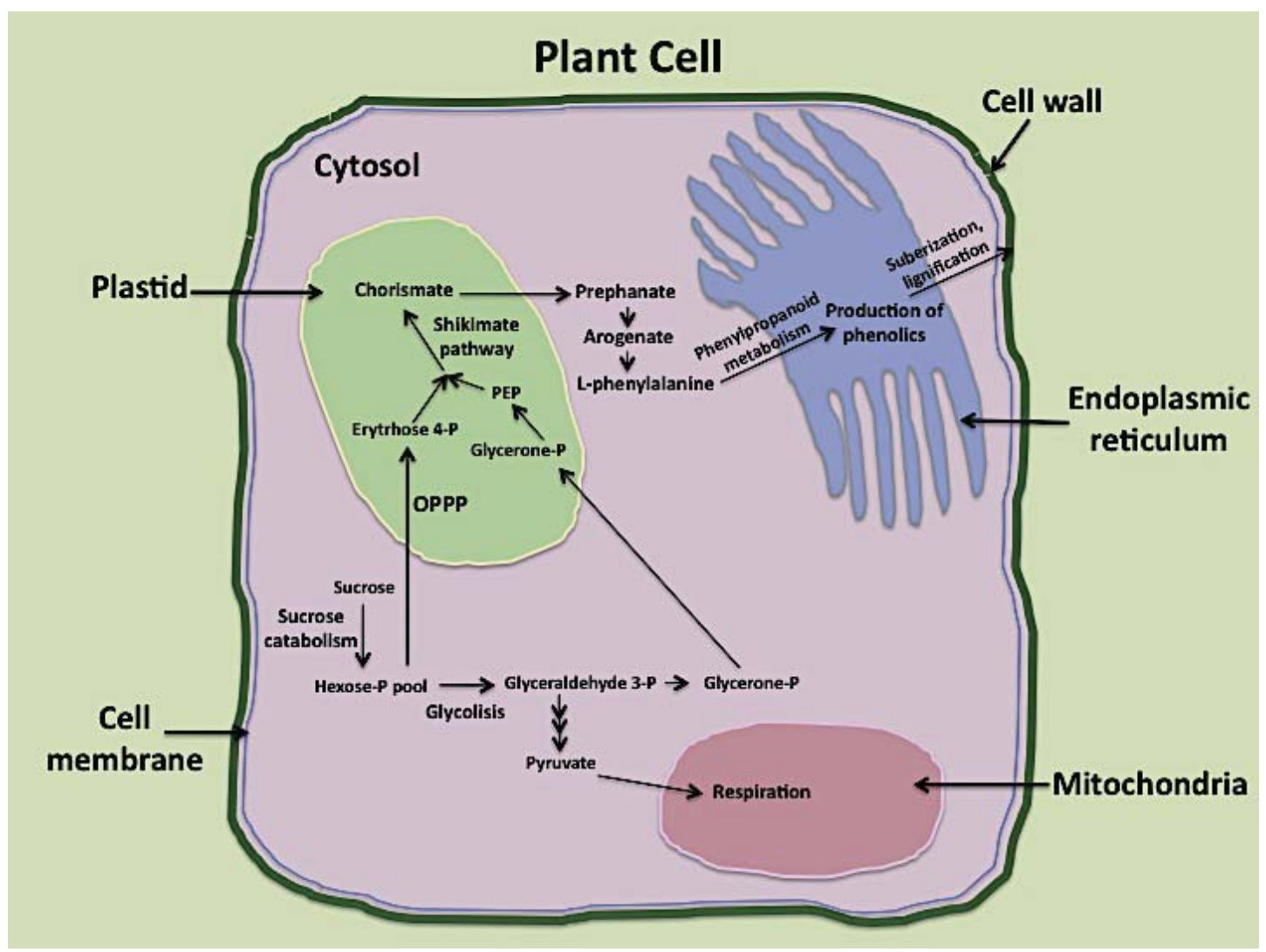

\subsection{Wound Healing and Accumulation of Hydroxycinnamic Acids in Plants}

Lignin and suberin are synthesized and deposited in wounded sites during wound healing to protect plants from water loss and pathogen attack [30,32]. Lignin is a polymer mainly derived from three hydroxycinnamyl alcohol monomers: p-coumaryl alcohol, coniferyl alcohol and sinapyl alcohol. On the other hand, suberin is an aliphatic-aromatic polyester. The aromatic domain of suberin is a lignin-like moiety composed of various substituted phenolics [32]. The high accumulation of hydroxycinnamic acids in wounded-tissue has been previously observed in different plants such as carrots [9,11], potato [33], and lettuce [34]. Since these phenolics are the substrate used for the 
synthesis of lignin and suberin during wound healing, their accumulation may be related with a higher rate of production than their polymerization (Figure 3). Other authors have proposed that the accumulation of soluble phenolics in stresses-tissue is not limited to the production of cell wall but also it may function to protect cells under stress conditions [31,35]. The biosynthesis of lignin as well as of the aromatic domain of suberin starts with the production of hydroxycinnamic acids that are converted to monolignols. These monolignols are then transported to the cell wall where they undergo oxidation and polymerization (Figure 2). Different types of enzymes such as peroxidases and laccases catalyze the dehydrogenative polymerization of monolignols. Peroxidases use $\mathrm{H}_{2} \mathrm{O}_{2}$ to oxidize monolignols whereas laccases utilize $\mathrm{O}_{2}[30]$.

Figure 3. Accumulation of antioxidant phenolic compounds during the wound healing process.

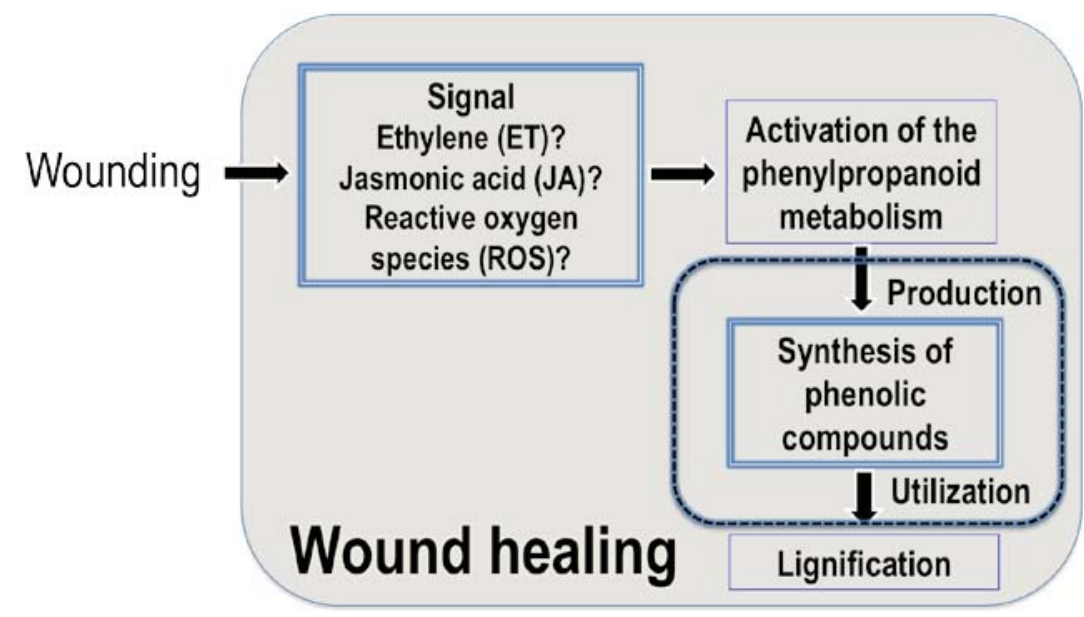

\subsection{Signaling Molecules Involved in the Wound-Induced Activation of the Phenylpropanoid Metabolism}

Signaling molecules such as ET, JA and ROS produced by wounding stress are reported to induce the synthesis of phenolics through the activation of the phenylpropanoid metabolism (Figure 3). JA and ROS are thought to be the main signaling molecules that induce the accumulation of hydroxycinnamic acids, lignin, and suberin in wounded plant tissues. Inhibitors of the action and biosynthesis of ET such as 1-methylcyclopropane (1-MCP, an inhibitor of ET action) and aminoethoxylvinylglycine (AVG, an inhibitor of ethylene biosynthesis) have been used to study the role of ET on the wound-induced accumulation of phenolics in tissues such as lettuce, carrots and Camptotheca acuminata. Saltveit [36] reported that the use of 1-MCP before or after the application of wounding stress does not affects the accumulation of phenolics in lettuce, thus the author suggested that ET synthesized by wounding does not act as signal for the wound-induced accumulation of phenolic compounds. In accordance with these observations, Heredia [5] reported that the application of 1-MCP in carrots pie-cuts does not reduce the wound-induced accumulation of hydroxycinnamic acids. Likewise, Kim et al. [37] determined that treating wounded Camptotheca acuminata tissue with AVG does not affect the gene expression of ferulate 5-hydroxylase ( $\mathrm{F} 5 \mathrm{H}$, a key enzyme in lignin biosynthesis). These observations suggest that endogenous ET produced as a response to wounding stress, does not have an evident effect as signaling molecule for the accumulation of phenolics and lignin on these wounded plant tissues. However, it has been reported that the exogenous application of ET induces higher accumulation of phenolics [9]. 
Similar experiments have been performed to evaluate the role of JA as signal for the wound-induced accumulation of soluble phenolics and lignin in plants. Inhibitors of JA biosynthesis such as $n$-alcohols, phenidione (PHEN), and salicylic acid (SA) have been applied in wounded lettuce, carrots, and Camptotheca acuminata, respectively. Choi et al. [38] exposed wounded-lettuce tissue to vapors $(20 \mu \mathrm{mol} / \mathrm{g} \mathrm{FW})$ or aqueous solutions $(100 \mathrm{mM})$ of $n$-alcohols. The authors found that treating wounded-lettuce with $n$-alcohols in vapor or aqueous solutions can decrease the tissue browning by $\sim 40$ and $60 \%$, respectively, suggesting a decreased synthesis of phenolic compounds and their further polymerization. Likewise, the application of PHEN $(10 \mathrm{mM})$ in carrot pie-cuts significantly reduced in $\sim 50 \%$ the wound-induced accumulation of hydroxycinnamic acids [5]. Kim et al. [37] demonstrated that the application of SA in wounded Camptotheca acuminata dramatically decreased the gene expression of $\mathrm{F} 5 \mathrm{H}$ in the tissue, thus potentially reducing the accumulation of lignin in the wounded tissue.

ROS are one of the signaling molecules associated with the activation of the phenylpropanoid metabolism [4,5,11], formation of suberin poly(phenolics) during suberization [39,40] and with the synthesis of lignin [37]. ROS are produced via a diphenyleneiodonium (DPI) chloride sensitive $\mathrm{Ca}^{2+}$-dependent reduced nicotinamide adenine dinucleotide phosphate (NADPH) oxidase. Upon stress NADPH oxidase produces superoxide radical $\left(\mathrm{O}_{2}{ }^{-}\right)$that is transformed into $\mathrm{O}_{2}$ and $\mathrm{H}_{2} \mathrm{O}_{2}$ by superoxide dismutase (SOD). It is well known that the production of $\mathrm{H}_{2} \mathrm{O}_{2}$ is essential for lignin biosynthesis since it is the substrate used by peroxidase to oxidize monolignols. It has been demonstrated that the wound-induced accumulation of hydroxycinnamic acids in carrots can be inhibited by treating the tissue with a solution-containing DPI [4,5,11]. In addition, it has been reported that processes such as suberilization and lignification can be inhibited by the application of DPI $[37,39,40]$.

\subsection{Wounding and the Synthesis of Aromatic Amino Acids (Carbon Source for Phenolics Biosynthesis)}

The wound-induced accumulation of hydroxycinnamic acids, lignin, and suberin in plants has to be related with the activation of metabolic events involved on the supplementation of carbons skeletons to the phenylpropanoid metabolism (Figure 2). Carbohydrates (starch and sucrose) are the substrates needed for the synthesis of phenolics. Phenolics biosynthesis, as well as respiration, starts in the cytosol of plant cells where sucrose is cleaved to produce glucose 6-P and fructose 6-P. Part of the hexose-P pool is transported to the plastid and converted to erythrose 4-P by the oxidative pentose-phosphate pathway (OPPP). The other fraction of the hexose-P pool is converted to glycerone-P in the cytosol by glycolysis. Glycerone-P is transported to the plastid and converted to phosphoenolpyruvate (PEP). Erythrose 4-P and PEP are the substrates for the shikimate pathway occurring in the plastid [41]. The shikimate pathway produces chorismate, which is used by chorismate mutase to synthesize prephanate. Prephanate is then converted to arogenate, which is subsequently transformed to L-phenylalanine. L-phenylalanine is used by phenylalanine ammonia-lyase (PAL) to initiate the synthesis of phenolic compounds as part of the phenylpropanoid mebolism that occurs in the endoplasmic reticulum of plant cells $[31,42]$.

As previously described herein, carrots can be used as biofactories of chlorogenic acids when subjected to extreme conditions of wounding stress. Therefore, it is suggested that all these metabolic 
pathways involved in the synthesis of L-phenylalanine are wound-induced in the plant cell to supply the carbon flux needed for phenolics biosynthesis (Figure 2). It is well known that respiration is increased in wounded-carrot tissue and that the respiration rate is dependent on the degree of wounding [43]. Likewise, the up-regulation of glycolytic enzymes in wounded tissues such as sugar beet has been previously reported and proposed as a potential mechanism to increase the flux of carbon compounds to support wound-healing process [44]. The activation of the OPPP by wounding is believed to play an important role in providing reducing power (NADPH) for lignin biosynthesis [45]. The wound-induced up-regulation of 3-Deoxy-D-arabino heptulosonate-7-phosphate synthase (DAHP synthase) and chorismate mutase, key regulatory enzymes of the shikimic acid pathway, has also been reported in Brassica juncea seedlings, tomato and potato [46,47].

\section{Conclusions}

Upon the application of wounding stress ET, JA, and ROS are produced which are key regulators of plant defense mechanisms. Although the up-regulation of the primary metabolism in wounded plants has been previously reported [46-48], the role of ET, JA, and ROS on activating these pathways is not fully understood. The activation of the primary metabolism may be crucial for the biosynthesis of secondary metabolites, since it generates the carbon skeletons (aromatic amino acids) needed for secondary metabolites production. In addition, the OPPP is the major source of NADPH, which is needed for different biochemical reactions occurring in the wounded carrot tissue, for instance lignin and ROS biosynthesis as well as ROS detoxification $[45,49]$.

Wounding stress up-regulates the expression of genes related with the biosynthesis of secondary metabolites with health promoting properties [6]. The involvement of ET, JA, and ROS on the accumulation of secondary metabolites has been previously studied by using inhibitors of their biosynthesis and/or action. These studies have demonstrated that these signaling molecules play an important role in the production and accumulation of phenolic compounds, ligning and suberin in wounded plant tissues such as lettuce, carrots, and Camptotheca acuminata [11,35-37,39,40].

The up-regulation of the primary and secondary metabolism induced by wounding stress in plants (Figure 4) suggests that primary and secondary metabolites of interest, such as shikimic acid and antioxidant phenolics, are being synthesized in the tissue [6]. This demonstrates the potential use of abiotic stresses as a tool for the production of high commercial value plant bioactives. However, for future commercial exploitation of this concept there is need to address several issues and factors including the understanding of molecular mechanisms of stress signals, effects on different categories of bioactive compounds (e.g., carotenoids, vitamin C, others), the response to stresses of different crops, the possible microbial growth during stress applications, among other factors. This is an exciting new area where much research is still needed. 
Figure 4. Wound-induced activation of pathways related with the biosynthesis of phenolic compounds in plants. Abbreviations: JA = Jasmonic acid; ET = Ethylene; ROS = Reactive oxygen species; OPPP = Oxidative pentose phosphate pathway; $\mathrm{PEP}=$ Phosphoenolpyruvate; E-4P = Erythrose-4 phosphate; PAL = Phenylananine ammonia-lyase; $\mathrm{C} 4 \mathrm{H}=$ Coumarate 4-hydroxylase; $4 \mathrm{CL}=4$-Coumarate CoA ligase.

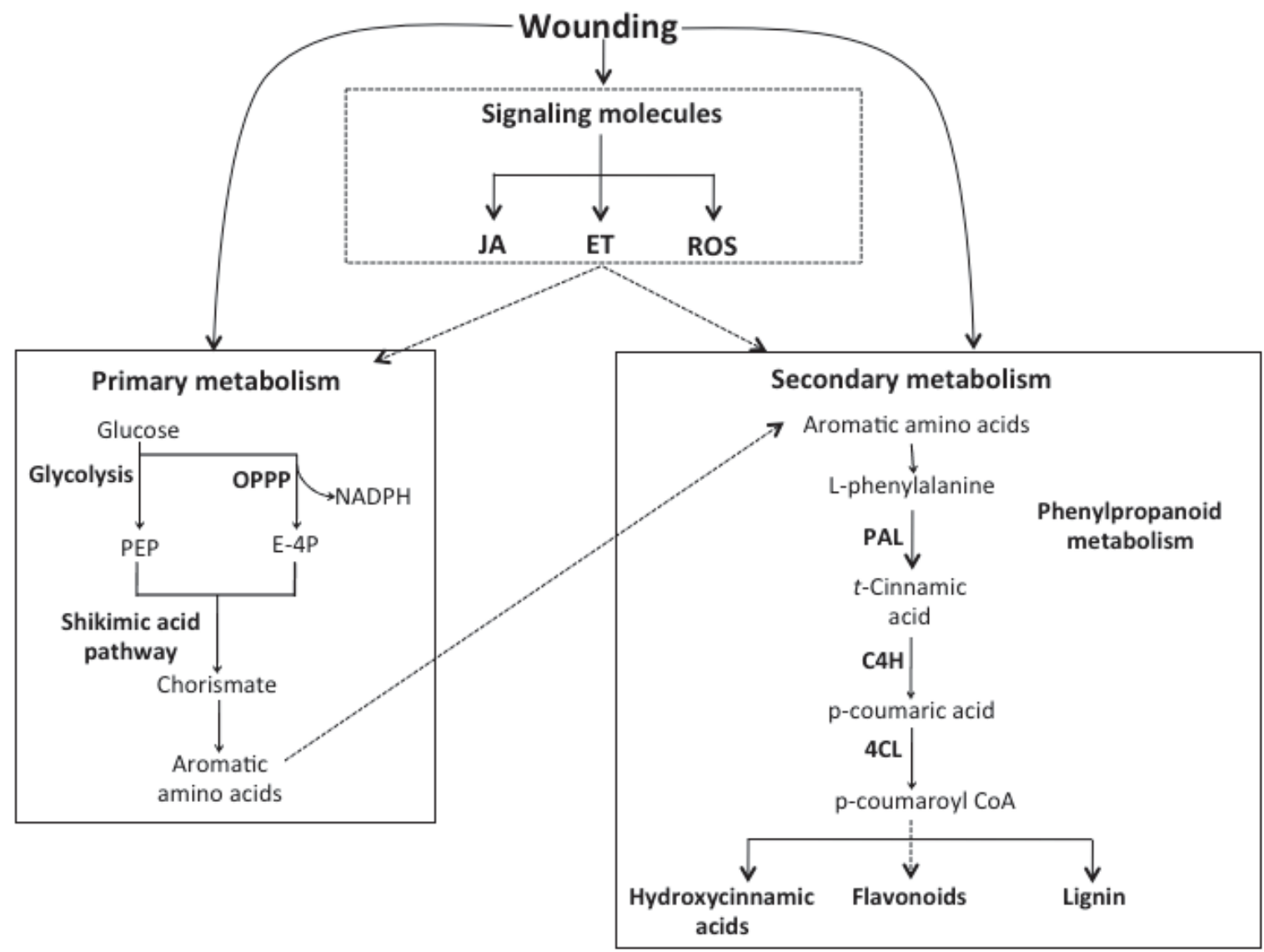

\section{Acknowledgments}

This study is based upon research supported by research funds from the Tecnológico de Monterrey Research Chair Initiative (CAT 161). In addition, this work was supported by the Cooperative State Research, Education, and Extension Service, U.S. Department of Agriculture under Agreement No. 2010-34402-20875 (2010-2013), "Designing Foods for Health" through the Vegetable \& Fruit Improvement Center, Texas AgriLife Research.

\section{References}

1. Flinn, J.E.; Zavon, J.A. Green plants as biofactories for drugs. Biopharm. Int. 2004, 17, 42-49.

2. Colwell, R.K.; Norse, E.A.; Pimentel, D.; Sharples, F.E.; Simberloff, D. Genetic engineering in agriculture. Science 1985, 229, 111-112.

3. Cisneros-Zevallos, L. The use of controlled postharvest abiotic stresses as a tool for enhancing the nutraceutical content and adding-value of fresh fruits and vegetables. J. Food Sci. 2003, 68, $1560-1565$. 
4. Surjadinata, B.B. Wounding and Ultraviolet Radiation Stresses Affect the Phenolic Profile and Antioxidant Capacity of Carrot Tissue. Ph.D. Thesis, Texas A\&M University, College Station, TX, USA, 2006.

5. Heredia, J.B. The Enhancement of Fresh Produce Antioxidant Capacity by Wounding Stress and Phytohormones. Ph.D. Thesis, Texas A\&M University, College Station, TX, USA, 2006.

6. Jacobo-Velázquez, D.A. Physiological and Molecular Mechanisms Governing the Postharvest Stress-Induced Accumulation of Antioxidant Phenolic Compounds in Carrots. Ph.D. Thesis, Texas A\&M University, College Station, TX, USA, 2010.

7. Surjadinata, B.B.; Cisneros-Zevallos, L. Biosynthesis of phenolic antioxidants in carrot tissue increases with wounding intensity. Food Chem. 2012, 134, 615-624.

8. Heredia, J.B.; Cisneros-Zevallos, L. The effect of exogenous ethylene and methyl jasmonate on the accumulation of phenolic antioxidants in selected whole and wounded fresh produce. Food Chem. 2009, 115, 1500-1508.

9. Heredia, J.B.; Cisneros-Zevallos, L. The effect of exogenous ethylene and methyl jasmonate on pal activity, phenolic profiles and antioxidant capacity of carrots (Daucus carota) under different wounding intensities. Postharvest Biol. Technol. 2009, 51, 242-249.

10. Jacobo-Velázquez, D.A.; Cisneros-Zevallos, L. Correlations of antioxidant activity against phenolic content revisited: A new approach in data analysis for food and medicinal plants. J. Food Sci. 2009, 74, R107-R113.

11. Jacobo-Velázquez, D.A.; Martínez-Hernández, G.B.; Rodríguez, S.; Cao, C.-M.; Cisneros-Zevallos, L. Plants as biofactories: Physiological role of reactive oxygen species on the accumulation of phenolic antioxidants in carrot tissue under wounding and hyperoxia stress. J. Agric. Food Chem. 2011, 59, 6583-6593.

12. Ye, X.; Al-Babili, S.; Klöti, A.; Zhang, J.; Lucca, P.; Beyer, P.; Potrykus, I. Engineering the provitamin A (beta411 carotene) biosynthetic pathway into (carotenoid-free) rice endosperm. Science 2000, 287, 303-305.

13. Niggeweg, R.; Michael, A.J.; Martin, C. Engineering plants with increased levels of the antioxidant chlorogenic acid. Nat. Biotechnol. 2004, 22, 746-754.

14. Diretto, G.; Al-Babili, S.; Tavazza, R.; Papacchioli, V.; Beyer, P.; Giuliano, G. Metabolic engineering of potato carotenoid content through tuber-specific over expression of a bacterial mini-pathway. PLOS ONE 2007, 2, e350.

15. Vinson, J.A.; Su, X.; Zubik, L.; Bose, P. Phenol antioxidant quantity and quality in foods: Fruits. J. Agric. Food Chem. 2001, 49, 5315-5321.

16. Heo, H.J.; Kim, Y.J.; Chung, D.; Kim, D.-O. Antioxidant capacities of individual and combined phenolics in a model system. Food Chem. 2007, 104, 87-92.

17. Reyes, L.F.; Cisneros-Zevallos, L. Wounding stress increases the phenolic content and antioxidant capacity of purple-flesh potatoes (Solanum tuberosum L.). J. Agric. Food Chem. 2003, 51, 5296-5300.

18. Reyes, L.F.; Villarreal, J.E.; Cisneros-Zevallos, L. The increase in antioxidant capacity after wounding depends on the type of fruit and vegetable tissue. Food Chem. 2007, 101, 1254-1262.

19. Olthof, M.R.; Hollman, P.C.H.; Katan, M.B. Chlorogenic acid and caffeic acid are absorbed in humans. J. Nutr. 2001, 131, 66-71. 
20. Olthof, M.R.; Hollman, P.C.H.; Buijsman, M.N.C.P.; van Amelsvoort, J.M.M.; Katan, M.B. Chlorogenic acid, quercetin-3-rutinoside and black tea phenols are extensively metabolized in humans. J. Nutr. 2003, 133, 1806-1814.

21. Farah, A.; Monteiro, M.; Donangelo, C.M.; Lafay, S. Chlorogenic acids from green coffee extract are highly bioavailabe in humans. J. Nutr. 2008, 138, 2309-2315.

22. Thom, E. The effect of chlorogenic acid enriched coffee on glucose absorption in healthy volunteers and its effect on body mass when used long-term in overweight and obese people. J. Int. Med. Res. 2007, 35, 900-908.

23. Wang, G.-F.; Shi, L.-P.; Ren, Y.-D.; Liu, Q.-F.; Liu, H.-.F.; Zhang, R.-J.; Li, Z.; Zhu, F.-H.; He, P.-L.; Tang, W.; et al. Anti-hepatitis B virus activity of chlorogenic acid, quinic acid and caffeic acid in vitro and in vivo. Antivir. Res. 2009, 83, 186-190.

24. Belkaid, A.; Currie, J.-C.; Desgagnés, J.; Annabi, B. The chemopreventive properties of chlorogenic acid reveal a potencial new role for the microsomal glucose-6-phosphate translocase in brain tumor progression. Cancer Cell Int. 2006, 6, 7:1-7:12.

25. Robinson, W.E., Jr.; Cordeiro, M.; Abdel-Malek, S.; Jia, Q.; Chow, S.A.; Reinecke, M.G.; Mitchell, W.M. Dicaffeoylquinic acid inhibitors of human immunodeficiency virus integrase: Inhibition of the core catalytic domain of human immunodeficiency virus integrase. Mol. Pharmacol. 1996, 50, 845-855.

26. Zhu, K.; Cordeiro, M.L.; Atienza, J.; Robinson, W.E., Jr.; Chow, S.A. Irreversible inhibition of human immunodeficiency virus type 1 integrase by dicaffeoylquinic acids. J. Virol. 1999, 73, 3309-3316.

27. Choi, J.; Park, J.K.; Lee, K.T.; Park, K.K.; Kim, W.B.; Lee, J.H.; Jung, H.J.; Park, H.J. In vivo antihepatotoxic effects of Ligularia fischeri var. spiciformis and the identification of the active component, 3,4-dicaffeoylquinic acid. J. Med. Food 2005, 8, 348-352.

28. Kim, S.-S.; Park, R.-Y.; Jeon, H.-J.; Kwon, Y.-S.; Chun, W. Neuroprotective effect of 3,5-dicaffeoylquinic acid on hydrogen peroxide-induced cell death in SH-SY5Y cells. Phytother. Res. 2005, 19, 243-245.

29. Rittinger, P.A.; Biggs, A.R.; Peirson, D.R. Histochemistry of lignin and suberin deposition in boundary layers formed after wounding in various plant species and organs. Can. J. Bot. 1987, 65, 1886-1892.

30. Boerjan, W.; Ralph, J.; Baucher, M. Lignin biosynthesis. Annu. Rev. Plant Biol. 2003, 54, 519-546.

31. Dixon, R.A.; Paiva, N.L. Stress-induced phenylpropanoid metabolism. Plant Cell 1995, 7, 1085-1097.

32. Franke, R.; Schreiber, L. Suberin-A biopolyester forming apoplastic plant interfaces. Curr. Opin. Plant Biol. 2007, 10, 252-259.

33. Cottle, W.; Kolattukudy, P.E. Biosynthesis, deposition, and partial characterization of potato suberin phenolics. Plant Physiol. 1982, 69, 393-399.

34. Tomás-Barerán, F.A.; Loaiza-Velararde, J.; Bonfanti, A.; Saltveit, M.E. Early wound- and ethylene-induced changes in phenylpropanoid metabolism in harvested lettuce. J. Am. Soc. Hort. Sci. 1997, 122, 399-404. 
35. Davey, M.W.; Franck, C.; Keulemans, J. Distribution, developmental and stress responses of antioxidant metabolism in Malus. Plant Cell Environ. 2004, 27, 1309-1320.

36. Saltveit, M.E. Effect of 1-methylcyclopropene on phenylpropanoid metabolism, the accumulation of phenolic compounds, and browning of whole and fresh-cut 'iceberg' lettuce. Postharvest Biol. Technol. 2004, 34, 75-80.

37. Kim, Y.J.; Kim, D.G.; Lee, S.H.; Lee, I. Wound-induced expression of the ferulate 5-hydroxylase gene in Camptotheca acuminata. Biochim. Biophys. Acta 2006, 1760, 182-190.

38. Choi, Y.-J.; Tomás-Barberán, F.A.; Saltveit, M.E. Wound-induced phenolic accumulation and browning in lettuce (Lactuca sativa L.) leaf tissue is reduced by exposure to $n$-alcohols. Postharvest Biol. Technol. 2005, 37, 47-55.

39. Bernards, M.A.; Razem, F.A. The poly(phenolic) domain of potato suberin: A non-lignin cell wall bio-polymer. Phytochemistry 2001, 57, 1115-1122.

40. Razem, F.A.; Bernards, M.A. Reactive oxygen species production in association with suberization: Evidence for an NADPH-dependent oxidase. J. Exp. Bot. 2003, 54, 935-941.

41. Herrmann, K.M.; Weaver, L.M. The shikimate pathway. Annu. Rev. Plant Phys. 1999, 50, 473-503.

42. Amthor, J.S. Efficiency of lignin biosynthesis: A quantitative analysis. Ann. Bot. 2003, 91, 673-695.

43. Surjadinata, B.B.; Cisneros-Zevallos, L. Modeling wound-induced respiration of fresh-cut carrots (Daucus carota L.). J. Food Sci. 2003, 68, 2735-2740.

44. Klotz, K.L.; Finger, F.L.; Anderson, M.D. Wounding increases glycolytic but not soluble sucrolytic activities in stored sugarbeet root. Postharvest Biol. Technol. 2006, 41, 48-55.

45. Pryke, J.A.; Rees, T. The pentose phosphate pathway as a source of NADPH for lignin synthesis. Phytochemistry 1977, 16, 557-560.

46. Dyer, W.E.; Henstrand, J.M.; Handa, A.K.; Herrmann, K.M. Wounding induces the first enzyme of the shikimate pathway in Solanaceae. Proc. Natl. Acad. Sci. USA 1989, 86, 7370-7373.

47. Sharma, R.; Jain, M.; Bhatnagar, R.K.; Bhalla-Sarin, N. Differential expression of DAHP synthase and chorismate mutase in various organs of Brassica juncea and the effect of external factors on enzyme activity. Physiol. Plant. 1999, 105, 739-745.

48. Keith, B.; Dong, X.N.; Ausubel, F.M.; Fink, G.R. Differential induction of 3-deoxy-D-arabinoheptulosonate 7-phosphate synthase genes in Arabidopsis thaliana by wounding and pathogenic attack. Proc. Natl. Acad. Sci. USA 1991, 88, 8821-8825.

49. Corpas, F.J.; Barroso, J.B.; Sandalio, L.M.; Distefano, S.; Palma, J.M.; Lupiáñez, J.A.; del Río, L.A. A dehydrogenase-mediated recycling system of NADPH in plant peroxisomes. Biochem. J. 1998, 330, 777-784.

(C) 2012 by the authors; licensee MDPI, Basel, Switzerland. This article is an open access article distributed under the terms and conditions of the Creative Commons Attribution license (http://creativecommons.org/licenses/by/3.0/). 